\title{
Microbial Transformation of Dihydroxyphenylacetic Acid by the Marine-Derived Bacterium Stappia sp.
}

\author{
Alain Simplice Leutou, Keumja Yun, and Byeng Wha Son* \\ Department of Chemistry, Pukyong National University, Busan 608-737, Korea. *E-mail: sonbw@pknu.ac.kr \\ Received May 9, 2014, Accepted May 30, 2014
}

Key Words : Stappia sp., Microbial transformation, 2-(3,4-Dihydroxyphenyl)acetic acid, Methyl 2-(5,6-dibromo-3,4-dihydroxyphenyl)acetate

The aim of our program is to explore the biological transformation of bioactive metabolites by the marine-derived microorganisms. As part of this program, we identified the marine-derived ascomycete strains and actinomycete strains that regioselectively oxidize bioactive natural products to new and more bioactive compounds: from terreusinone to the unsymmetrical alcohol derivative, terreusinol, by Streptomyces sp., ${ }^{1}$ from $6-n$-pentyl- $\alpha$-pyrone to two oxidized metabolites, 6- $n$-(4-oxopentyl)- $\alpha$-pyrone and 6- $n-[(S)-1-$ hydroxypentyl]- $\alpha$-pyrone, by Streptomyces sp., ${ }^{2}$ from cyclonerodiol to three metabolites, 10(Z)-, 10(E)-cyclonerotriol, and cyclonerodiol mannopyranoside, by the genus of Streptomyces and Penicillium, ${ }^{3}$ from geraniol to its 7-oxidized metabolite, 1,7-dihydroxy-3,7-dimethyl-(E)-oct-2-ene, by Hypocrea sp., ${ }^{4}$ from (-)-mellein to $(3 R, 4 S)$-4-hydroxymellein by Stappia sp., ${ }^{5}$ and from chlorogentisyl alcohol to 1-O-( $\alpha-\mathrm{D}-$ mannopyranosyl)chlorogentisyl alcohol by Chrysosporium synchronum. ${ }^{6}$

In our continuing study of applications of microbial transformations, we screened a lot of cultures for their ability to biotransform 2-(3,4-dihydroxyphenyl)acetic acid (1), ${ }^{7,8}$ and a marine isolate of the bacterium Stappia sp. was selected as the biotransforming target strain.

This report describes the isolation, identification, and radical scavenging activity of a new methyl 2-(5,6-dibromo3,4-dihydroxyphenyl)acetate (2) and a known analog, methyl 2-(2,5-dibromo-3,4-dihydroxyphenyl)acetate (3) (Figure 1). ${ }^{8}$

Microbial transformation of $\mathbf{1}$ was carried out under the condition of halide-enriched culture medium using the marine-derived bacterium Stappia sp. according to a twostage fermentation protocol. ${ }^{9}$

TLC analysis showed that the composition of the extract derived from fermentation in the halide-enriched culture medium differed from that derived from halide-free culture fermentation. In addition to the substrate 1, several new spots were detected in the former extract by TLC analysis; these were subsequently purified by repeated silica gel flash chromatography ( $n$-hexane in ethyl acetate) and HPLC [octadesyl silica (ODS)-A, $\mathrm{MeOH}-\mathrm{H}_{2} \mathrm{O}$ ] to yield a new compound $\mathbf{2}$ and a known compound $\mathbf{3}$.

Methyl 2-(5,6-dibromo-3,4-dihydroxyphenyl)acetate (2) was obtained in the form of a slightly yellow solid. It showed isotopic clusters at $m / z 338\left[\mathrm{M}\left({ }^{79} \mathrm{Br}_{2}\right)\right]^{+}(9), 340\left[\mathrm{M}\left({ }^{79} \mathrm{Br}\right.\right.$,

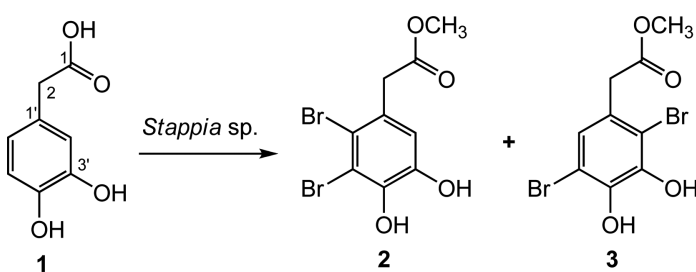

Figure 1. Microbial transformation of 2-(3,4-dihydroxyphenyl)acetic acid (1) to two dibrominated metabolites ( 2 and $\mathbf{3})$ by the marine-derived bacterium Stappia sp.

$\left.\left.{ }^{81} \mathrm{Br}\right)\right]^{+}(18)$, and $342\left[\mathrm{M}\left({ }^{81} \mathrm{Br}_{2}\right)\right]^{+}(8)$ with a ratio of $1: 2: 1$ in the EI-MS (Figure S1 in the Supporting Information), suggesting the presence of two bromine atoms. A molecular formula of $\mathrm{C}_{9} \mathrm{H}_{8} \mathrm{Br}_{2} \mathrm{O}_{4}$, which gave five degrees of unsaturation, was established by HR-EI-MS and ${ }^{13} \mathrm{C}-\mathrm{NMR}$. The IR spectrum of compound 2 exhibited band characteristics of hydroxyl $\left(3513 \mathrm{~cm}^{-1}\right)$ and ester $\left(1736,1175 \mathrm{~cm}^{-1}\right)$ functionalities. The general features of the UV, IR, and NMR spectra closely resembled those of compound $3,{ }^{8}$ except for the HMBC data. The positions of the two bromines in compound 2 were determined by HMBC. The key HMBC correlations (from $1-\mathrm{OCH}_{3}$ to $\mathrm{C}-1$; from $\mathrm{H}_{2}-2$ to $\mathrm{C}-1, \mathrm{C}-1$ ', 2', and $\mathrm{C}-6$ '; and from $\mathrm{H}-2$ ' to $\mathrm{C}-2, \mathrm{C}-4^{\prime}$, and C-6') showed the positions of the 5',6'-dibromo and 3',4'-dihydroxyl groups on the phenyl ring (Figure S4 in the Supporting Information). Detailed

Table 1. NMR spectral data for methyl 2-(5,6-dibromo-3,4-dihydroxyphenyl)acetate (2) ${ }^{a}$

\begin{tabular}{ccc}
\hline \multirow{2}{*}{ Carbon No. } & \multicolumn{2}{c}{$\mathbf{2}$} \\
\cline { 2 - 3 } & $\delta_{\mathrm{H}}$ (mult.) & $\delta_{\mathrm{C}}$ (mult.) \\
\hline 1 & & $170.8(\mathrm{qC})$ \\
2 & $3.73(\mathrm{~s})$ & $41.8\left(\mathrm{CH}_{2}\right)$ \\
$1^{\prime}$ & & $126.1(\mathrm{qC})$ \\
$2^{\prime}$ & $6.84(\mathrm{~s})$ & $117.3(\mathrm{CH})$ \\
$3^{\prime}$ & & $143.8(\mathrm{qC})$ \\
$4^{\prime}$ & & $145.0(\mathrm{qC})$ \\
$5^{\prime}$ & & $113.1(\mathrm{qC})$ \\
$6^{\prime}$ & & $115.6(\mathrm{qC})$ \\
$1-\mathrm{OMe}$ & $3.60(\mathrm{~s})$ & $51.8\left(\mathrm{CH}_{3}\right)$ \\
\hline
\end{tabular}

${ }^{a}$ Recorded in $d_{6}$-DMSO at $400 \mathrm{MHz}\left({ }^{1} \mathrm{H}\right)$ and $100 \mathrm{MHz}\left({ }^{13} \mathrm{C}\right)$. 
analyses of the ${ }^{1} \mathrm{H}$ - and ${ }^{13} \mathrm{C}-\mathrm{NMR}$ spectra of compound $\mathbf{2}$, including the results from DEPT, COSY, HMQC, and HMBC experiments, enabled its structure to be assigned as methyl 2-(5,6-dibromo-3,4-dihydroxyphenyl)acetate (see Table 1 and Figures S2 and S3 in the supplementary information).

The known methyl 2-(2,5-dibromo-3,4-dihydroxyphenyl)acetate (3) was also found during this study. It was identified from NMR spectra and from comparison with published data values. $^{8}$

There is considerable recent evidence that free radicals induce oxidative damage to biomolecules. This oxidative damage is considered to play a causative role in aging and several degenerative diseases such as Alzheimer's disease, rheumatoid arthritis, cancer, and atherosclerosis. ${ }^{10}$ The antioxidant activity was assessed on the basis of the radical scavenging effect on the DPPH free radical. Compounds 1-3 exhibited significant radical scavenging activity against DPPH with $\mathrm{IC}_{50}$ values $(11.0,12.0$, and $12.1 \mu \mathrm{M}$, respectively) demonstrating stronger activity than the positive control ( $L$-ascorbic acid; $\left.\mathrm{IC}_{50}, 20.0 \mu \mathrm{M}\right)$.

Compound 1 was also found to induce down regulation of epidermal growth factor activated mitogenic signaling cascade in Hela cells. ${ }^{11}$ Thus, we plan to assess the inhibitory activity of compounds $\mathbf{2}$ and $\mathbf{3}$ against the epidermal growth factor receptor (EGFR), ${ }^{12,13}$ and the results will be reported in due course.

\section{Experimental}

General. UV/visible spectra were measured on a Hitachi U-2001 UV/Vis spectrometer. IR spectra were recorded on a Bruker FT-IR model IFS-88 spectrometer. ${ }^{1} \mathrm{H}-(400 \mathrm{MHz})$ and ${ }^{13} \mathrm{C}$-NMR $(100 \mathrm{MHz})$ spectra were obtained on a JEOL JNM-ECP 400 NMR spectrometer, using TMS or solvent peaks [DMSO- $d_{6}:{ }^{1} \mathrm{H}(\delta 2.50)$ and $\left.{ }^{13} \mathrm{C}(\delta 39.5)\right]$ as reference standard. LC-MS and MS spectra were obtained on API 2000 (Applied Bio System) and IT-TOF (Shimadzu, Japan) spectrometer, respectively. HPLC was performed on a Young Lin ACME HPLC system using a reversed-phase analytical column (Gemini C18, $4.6 \times 250 \mathrm{~mm}, 5 \mu \mathrm{m}$ ) with UV detection. Incubations of microorganisms and microbial transformation were performed on an Incubator Shaker JS-FS2500 (Johnsam Co., Inchon, Korea).

Isolation of the Marine-Derived Bacterium Stappia sp. The Stappia sp., isolated from the surface of the edible marine green alga Enteromorph compressa (Korean name: NapJag PaRae), had light gray, downy, and soft white vegetative mycelia, and was identified on the basis of morphology and 16S rRNA analysis (SolGent Co., Ltd., Daejeon, Korea), identity of $99 \%$. The Stappia sp., designated as BAac008, is deposited at Pukyong National University, South Korea.

Microbial Transformation of 2-(3,4-Dihydroxyphenyl)acetic Acid (1). A two-stage culture protocol ${ }^{9}$ was used to obtain metabolites $\mathbf{2}$ and $\mathbf{3}$ on a preparative scale.

The SS medium consisting of soytone $(0.1 \%)$, soluble starch $(1.0 \%)$, and seawater $(100 \%)$ was autoclaved at 121
${ }^{\circ} \mathrm{C}$ for 15 min after addition of $\mathrm{NaBr}$ and $\mathrm{CaBr}_{2}$ (each 50 $\mathrm{mM}){ }^{14,15}$ The preparative culture (stage 1) was incubated in $1 \mathrm{~L}$ sterile medium in a $3 \mathrm{~L}$ culture flask on a rotary shaker (130 rpm) at $29{ }^{\circ} \mathrm{C}$ for 1 week. A $10 \%$ inoculum derived from the 1-week-old preparative culture was used to initiate the stage II culture $(1 \mathrm{~L})$, which was incubated for a further $24 \mathrm{~h}$ under the same conditions before addition of $20.0 \mathrm{mg}$ of compound 1 in $1.0 \mathrm{~mL}$ of $N, N$-dimethyl formamide (DMF)$\mathrm{MeOH}(3: 1 \mathrm{v} / \mathrm{v})$. Incubation was continued for two weeks in the same manner as described above. The substrate control consisted of sterile medium and substrate incubated under the same conditions, but without microorganisms. The culture control consisted of the microorganism grown under the same condition, but without substrate. After three weeks, each control was harvested and analyzed by TLC. TLC analyses showed that the composition of the extract differed from those derived from two controls.

Extraction and Isolation. The mycelium and broth were separated by filtration through the cheesecloth, and the whole broth was extracted with EtOAc (1 liter) to afford broth extract $(60 \mathrm{mg})$. A portion of this extract $(55 \mathrm{mg})$ was subjected to $\mathrm{Si}$ gel flash chromatography. Elution was performed with $n$-hexane-EtOAc (stepwise, 0-100\% EtOAc) to yield twenty collections $(50 \mathrm{~mL}$ each). These collections were pooled on the basis of their TLC profiles to give five combined fractions. Fractions 2 and 4 were separated by medium pressure liquid chromatography (MPLC) (ODS) using a $\mathrm{H}_{2} \mathrm{O}-\mathrm{MeOH}$ gradient elution to afford crude substrate (1) and two metabolites $(\mathbf{2}, \mathbf{3})$, respectively. These were further purified by HPLC (Gemini C18, $4.6 \times 250 \mathrm{~mm}$, $1 \mathrm{~mL} / \mathrm{min}$ ) utilizing a $30 \mathrm{~min}$ gradient program of $50 \%$ to $100 \% \mathrm{MeOH}$ in $\mathrm{H}_{2} \mathrm{O}$ to furnish compounds 1 (4.0 mg), 2 (6.5 mg), and 3 (5.5 mg), respectively.

Methyl 2-(5,6-dibromo-3,4-dihydroxyphenyl)acetate (2): A colorless solid; IR (KBr) $v_{\max } 3513,3290,1736,1603$, 1589, 1408, 1349, 1278, 1203, 1175, 1024, 983, 855, 736 $\mathrm{cm}^{-1}$; UV $\lambda_{\max }(\mathrm{MeOH})(\log \varepsilon) 294(3.28) \mathrm{nm} ;{ }^{1} \mathrm{H}-\mathrm{NMR}\left(d_{6^{-}}\right.$ DMSO, $400 \mathrm{MHz})$ and ${ }^{13} \mathrm{C}-\mathrm{NMR}\left(d_{6}\right.$-DMSO, $\left.100 \mathrm{MHz}\right)$ : see Table 1 and Figures $\mathrm{S} 2$ and $\mathrm{S} 3$ in the supplementary information; LR-EI-MS m/z: $342\left[\mathrm{M}\left({ }^{81} \mathrm{Br}_{2}\right)\right]^{+}(8), 340\left[\mathrm{M}\left({ }^{79} \mathrm{Br}\right.\right.$, $\left.\left.{ }^{81} \mathrm{Br}\right)\right]^{+}(18), 338\left[\mathrm{M}\left({ }^{79} \mathrm{Br}_{2}\right)\right]^{+}(9), 283\left[342-\mathrm{CO}_{2} \mathrm{CH}_{3}\right]^{+}(44)$, $281\left[340-\mathrm{CO}_{2} \mathrm{CH}_{3}\right]^{+}(90), 279\left[338-\mathrm{CO}_{2} \mathrm{CH}_{3}\right]^{+}(44), 261$ $\left[342-{ }^{81} \mathrm{Br}\right]^{+}(95), 259\left[338-{ }^{79} \mathrm{Br}\right]^{+}(100), 233(15), 231(17)$, 203 (6), 201 (13), 199 (7), 180 (14) (see Figure S1 in the supplementary information); HR-EI-MS $\mathrm{m} / \mathrm{z} 341.8749$ $\left.\left[\mathrm{M}^{81} \mathrm{Br}_{2}\right)\right]^{+}$(calcd for $\left.\mathrm{C}_{9} \mathrm{H}_{8} \mathrm{O}_{4}{ }^{81} \mathrm{Br}_{2}, 341.8748\right)(+0.3 \mathrm{ppm})$, $m / z 339.8772\left[\mathrm{M}\left({ }^{79} \mathrm{Br},{ }^{81} \mathrm{Br}\right)\right]^{+}$(calcd for $\mathrm{C}_{9} \mathrm{H}_{8} \mathrm{O}_{4}{ }^{79} \mathrm{Br}^{81} \mathrm{Br}$, $339.8769)$ (+0.9 ppm), m/z $337.8787\left[\mathrm{M}\left({ }^{79} \mathrm{Br}_{2}\right)\right]^{+}$(Calcd for $\left.\mathrm{C}_{9} \mathrm{H}_{8} \mathrm{O}_{4}{ }^{79} \mathrm{Br}_{2}, 337.8789\right)(-0.7 \mathrm{ppm})$.

Methyl 2-(2,5-dibromo-3,4-dihydroxyphenyl)acetate (3): Spectroscopic data were virtually identical to those reported in the literature. ${ }^{8}$

Radical Scavenging Activity Against DPPH. ${ }^{16}$ Samples (compounds 1-3, and positive control, $L$-ascorbic acid) to be tested were dissolved in $\mathrm{MeOH}$ and the solution $(160 \mathrm{~mL})$ was dispensed into wells of a 96-well microtiter tray. $40 \mathrm{~mL}$ of the DPPH solution in $\mathrm{MeOH}\left(1.5 \times 10^{-4} \mathrm{M}\right)$ was added to 
each well. The mixture was shaken and left to stand for 30 min, and the absorbance of the resulting solution was measured at $520 \mathrm{~nm}$ with microplate reader (Packard Co., Spectra Count ${ }^{\mathrm{TM}}$ ). The scavenging activity on DPPH radical was expressed as $\mathrm{IC}_{50}$, which is the concentration of the tested compound required to give a $50 \%$ decrease of the absorbance from that of the blank solution [consisting of $\mathrm{MeOH}(160 \mathrm{~mL})$ and DPPH solution $(40 \mathrm{~mL})]$.

Acknowledgments. This work was supported by a Research Grant of Pukyong National University (2014 year).

Supporting Information. LR-MS, ${ }^{1} \mathrm{H}-\mathrm{NMR},{ }^{13} \mathrm{C}-\mathrm{NMR}$, and HMBC spectra of compound 2.

\section{References}

1. Li, X.; Lee, S. M; Choi, H. D.; Kang, J. S.; Son, B. W. Chem. Pharm. Bull. 2003, 51, 1458-1459.

2. Li, X.; Kim, S.-K.; Jung, J. H.; Kang, J. S.; Choi, H. D.; Son, B. W. Bull. Korean Chem. Soc. 2005, 26, 1889-1890.

3. Li, X.; Kim, Y. H.; Jung, J. H.; Kang, J. S.; Kim, D.-K.; Choi, H.
D.; Son, B. W. Enz. Microbial Technol. 2007, 40, 1188-1192.

4. Leutou, A. S.; Yang, G.; Nenkep, V. N.; Siwe, X. N.; Feng, Z.; Khong, T. T.; Choi, H. D.; Kang, J. S.; Son, B. W. J. Microbiol. Biotechnol. 2009, 19, 1150-1152.

5. Feng, Z.; Nenkep, V. N.; Yun, K.; Zhang, D.; Choi, H. D.; Kang, J. S.; Son, B. W. J. Microbiol. Biotechnol. 2010, 20, 985-987.

6. Yun, K.; Kondempudi, C. M.; Choi, H. D.; Kang, J. S.; Son, B. W. Chem. Pharm. Bull. 2011, 59, 499-501.

7. Li, X.; Kim, S.-K.; Kang, J. S.; Choi, H. D.; Son, B. W. J. Microbiol. Biotechnol. 2006, 16, 637-638.

8. Leutou, A. S.; Yun, K.; Kang, J. S.; Son, B. W. Chem. Pharm. Bull. 2013, 61, 483-485.

9. Smith, R. V.; Rosazza, J. P. J. Pharm. Sci. 1975, 64, 1737-1759.

10. Chung, H. Y.; Choi, H. R.; Park, H. J.; Choi, J. S.; Choi, W. C. J. Agric. Food. Chem. 2001, 49, 3614-3621, and references cited therein.

11. Jo, M. J.; Bae, S. J.; Son, B. W.; Kim, C. Y.; Kim, G. D. Cancer Cell International 2013, 13, 1-9.

12. Ranson, M. Br. J. Cancer 2004, 90, 2250-2255.

13. Jorissen, R. N.; Walker, F.; Pouliot, N.; Garrett, T. P.; Ward, C. W.; Burgess, A. W. Exp. Cell Res. 2003, 284, 31-53.

14. Stadler, M.; Anke, H.; Sterner, O. J. Antibiot. 1995, 48, 149-153.

15. Stadler, M.; Anke, H.; Sterner, O. J. Antibiot. 1995, 48, 261-266.

16. Li, Y.; Li, X.; Son, B. W. Nat. Prod. Sci. 2005, 11, 136-138. 